\title{
PERKERASAN BETON SEMEN
}

Oleh : Ir. Edy Purwanto

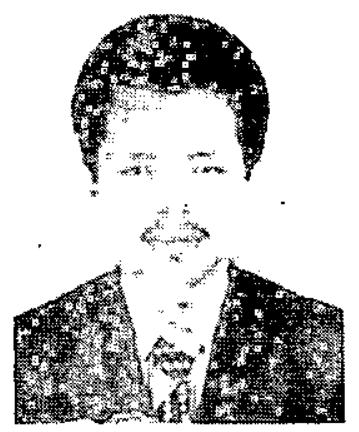

Ir. Edy Purwanto adalah tenaga edukatif tetap pada Fakultas Teknik (Jurusan Teknik Sipil) Universitas Islam Indonesia (sejak tahun 1984).

Di lahirkan di Gombong pada tanggal 21 Agustus 1957.

Edy adalah alumnus Fakultas

Teknik Sipil UIl; pernah menjadi. konstruktor Biro Perencanaan dan Konsultan Bangunan Sipil CV. Cipta Utami Yogyakarta (1981-1983), konstruktor dan koordinator Pengawas Biro Perencanaan dan Konsultan PT Candra Kirana Total Design Yogyakarta (1983-1984) dan Direktur Teknik Developer PT Kaur Jaya Yogyakarta (1985 sampai sekarang):

\section{Pendahulusn}

Penggunaan beton semen, sebagai bahan perkerasan jalan masih jarang dilakukan di Indonesia, akan tetapi pemakaiannya sebagai perkerasan pada tempat-tempat parkir, hardstanding di pabrik-pabrik dan jalan-jalan utama kian hari semakin meningkat. Perkerasan beton semen dipakai karena mempunyai beberapa keunggulan dibandingkan dengan jalan aspal. Yaitu lebih kuat dan cocok untuk jalan-jalan utama yang bisa menampung beban-beban berat dan dalam perhitungan jangka panjang biaya lebih murah dibandingkan dengan aspal. Disamping itu pemakaian semen juga dapat menghemat devisa, mengingat sampai saat ini sebagian besar aspal . masih harus diimpor.

Perkerasan beton semen yang baik dituntut syarat kwalitas dan kekuatan yang mencukupi, dihampar pada elevasi dengan profil melintang pada batasbatas toleransi, penghamparan di atas permukaan tanah yang mempunyai daya dukung seragam. Subgrade maupun subbase harus memenuhi kadar air dan kepadatan yang diisyaratkan, serta diadakan "proof rolling" sebelum campuran beton semen dihamparkan diatas material-material tersebut. Penghamparan beton semen sempurna apabila" bekisting dipasang dengan tepat, dimen- 
si "pérkerrasan " beton semen, evelasi, sambungan, pembesian dan keiengkapan lainnya diletakkan pada posisi yang benar.

Untuk menjamin agar perkerasan beton ini kuat dan berumur panjang, hendaknya dijaga betul pada saat "curing" dan diamankan terhadap bebán lalu lintas kendaraan sebélum mencapai kekuatan beton yang cukup.

\section{BEBERAPA URAIAN PEKERAS- AN BETON SEMEN}

Seperti pada umumnya konstruksi bangunan, perkerasan beton semen mempunyai bagian-bagian sebagai berikut :

\subsection{SUBGRADE :}

tanah dasar galian ("cut") atau timbunan ("embankment") dan dapat mempengaruhi perencanaan, ketebalan perkerasän beton semen.

Sebelum pemasangan "subgrade", pada permukaan tanah yang sudah sempurna, "subgrade" harus di "proof rolled" dengan roller berat untuk memeriksa bagian-bagian yang lemah. Bila terdapat material yang mengakibatkannya tidak stabil, harus dibuang dan diganti material yang baik dan dipadatkan. Permukaan subgrade harus mempunyai bentuk "crown" setiap saat untuk menjaminnya mengalirkan air hujan dari permukaan badan jalan. Air hujan harus dialirkan dari muka pembuang samping pada taluid.

\subsection{SUBBASE}

material pilihan, direncanakan dengan ketebalan tertentu, diletakkan sebagai pondasi perkerasan beton semen.

Material pilihan dihamparkan di atas subgrade untuk menahan perkerasan beton semen.
Tujuannya untuk menahan "pumping"; memperbaiki drainasi, mengontrol kadar air dalam lapisan subgrade, memperbaiki dukungan terhadap perkerasan beton semen, mengontrol perubahan volume pada subgrade sehingga mengurangi kerugian pada perkerasan beton semen dan memberikan kepastian kepada konstruksi perkerasan beton semen.

\subsection{SHOULDER :}

bagian badan jalan antara ujung tepi perkerasan beton semen dengan tepi atas parit pada galian atas puncak talud pada timbunan. Apabila dikehendaki sebagai "hard shouder" bisa menggunakan jenis material yang sama untuk subbase. Selanjutnya bisa juga digunakan beton K-175 apabila dipergunakan untuk pejalan kaki (trotoir).

\subsection{JOINT :}

sambungan antara dua bagian perkerasan beton semen atau antara perkerasan beton semen dengan jembatan, berupa sambungan memanjang ("longitudinal") atau melintang ("transversal"). Ada 4 (empat) joint yang kita kenal :

1. "Construction joint", untuk longitudinal maupun transversal.

2. "Longitudinal center joint", "hinged joint" untuk menghilangkan tegangan lentur.

3. "Contruction joint" dalam arah melintang jalan.

4. "Expansion joint", sepenuhnya tebal perkerasan dengan "filler" untuk menutup joint meskipun perkerasan beton semen mengembang.

\subsection{SUFACE TEXTURE :}

karakter permukaan beton semen sebagai bentuk kerjaan akhir.

a. Setelah campuran beton semen 
mengeras pengawas harus segera memeriksa permukaan perkerasan beton semen, apa seseuai dengan toleransi yang diberikan pada saat perkerasan beton semen belum kering, dengan menarik gerak kawat halus yang sudah disiapkan sebelumnya dalam arah tegak lurus longitudinal joint atau juga sejajar.

b. "Curing".

Pengerasan dan kekuatan perkerasan beton semen sangat tergantung kepada proses "hidrasi". Umur perkerasan beton semen dan lamanya pemakaian sangat tergantung pada cara "curing". Spesifikasi menunjukan cara "curing" dan pengamanannya dan dilakukan sebagaimana mestinya. Yang paling umum untuk "curing" adalah "waterproof membranc" dan "ploy thelene sheet". Keuntungan pemakaian "polithelene" adalah bisa melindungi permukaan perkerasan dari pengaruh air hujan.

\subsection{S L A B :}

perkerasan beton semen.

a. Pelaksanaan perkerasan beton semen.

Tahapan pelaksanaan harus diperhatikan sungguh-sungguh mulai dari pembersihan tanah sampai pada akhirnya dibuka untuk lalu lintas kendaraan umum. Pelaksanaan perkerasan beton semen termasuk menghampar, memadatkan, meratakan, membuat texture permukaan, "curing" dan pengamanan hasil pekerjaan tersebut. Apabila hasil pekerjaan tidak baik/kurang sempurna, akan mengakibatkan retak dan hancur pada perkerasan, demikian juga penggunaan material yang kurang tepat akan berakibat umur perkerasan tidak akan lama.

b. Penghamparan beton semen bisa dilakukan dengan cara : - manual - mekanis.

Cara manual.

Penghamparan dilakukan sepanjang batang besi perata. Seteiah getaran, campuran beton semen pada permukaan diratakan untuk memberikan permukaan yang rata.

Cara mekanis.

Dengan cara mekanis kecepatan pelaksanaan cukup tinggi ( bisa $1,50-3,00 \mathrm{~km}$ per hari ) dan bisa mengurangi jumlah pekerja sehingga jumlah biaya menjadi murah. Pemadatan lebih merata dan bentuk permukaan yang rata bila didukung oleh peralatan pada kondisi baik serta operator terlatih baik.

\subsection{O W E L :}

besi beton bundar yang dipasang melintang sambungan (joint) untuk memindahkan sebagian dari beban yang diterima salah satu bagian perkerasan beton semen (slab) kebagian perkerasan lain yang berdekatan. Bila diletakkan pada sambungan pengembangan (expansion joint), besi harus ditutup (cap) atau diberi pembalut (sleeves) pada ujung bebasnya, dimana besi beton dapat bergerak meskipun sambungan tertutup.

- "Tie bars" atau "Tie bolts" : besi beton bergerigi (deformed bars) atau besi beton dibengkok, dipasang melintang pusat sambungan konstruksi (construction joint) untuk mengikat perkerasan beton semen diantara kedua bagian yang berdekatan dan menjaga agar sambungan tidak terbuka.

- "Distributed steel" : anyaman besi beton dengan las dipasang pada per- 
kerasan beton semen untuk menghindarkan retak dan diharapkan mengikat dengan kuat.

Gambar 1. JOINTING OF CONCRETE PAVEMENT

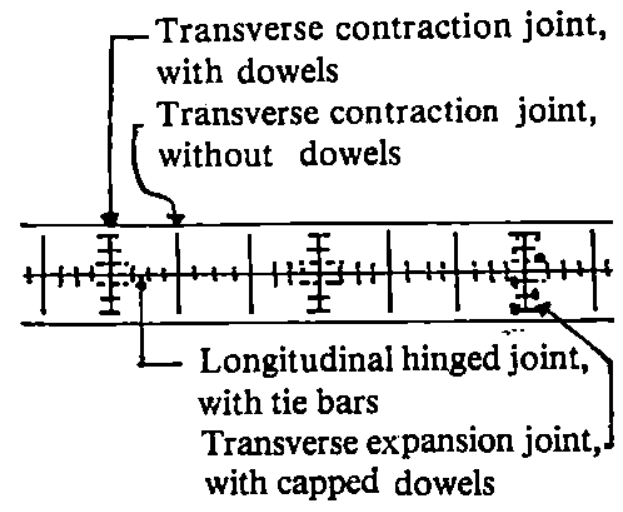

\section{PERILAKU PERKERASAN.}

Perilaku perkerasan jalan sampai saat ini dianggap belum secara keseluruhan tuntas diketahui mekanismenya, salah satu sebab adalah karena banyaknya faktor luar yang berpengaruh terhadap sistem kerjanya. Pendekatan awal adalah simulasi teoritis dari Business yang mengendalikan beban roda disebarkan ke tanah yang berupa bahan homogen. Asumsi ini kemudian diperbaiki oleh Burmister dengan teori 2 (dua) lapis, dan selanjutnya oleh ahli lain dikembangkan lagi menjadi teori multi lapis.

Perjalanan gaya-gaya berawal dari beban roda sampai ketanah dasar (subgrade) tidaklah sejelas/gamblang sebagaimana perjalanan gaya-gaya pada sebuah rangka jembatan. Beberapa hal menimbulkan perbedaan besat antara lain :

1. Beban yang bekerja sécara dominan adalah beban dinamis.
2. Bahan-bahan perkerasan adalah bahan-bahan yang pada umumnya tidak homogen dan bersifat visco elastis.

3. Keadaan cuaca yang sangat berpengaruh terhadap perilaku bahanbahan perkerasan tersebut

4. Tanah dasar sangat bervariasi yang dipengaruhi oleh keadaan geologi setempat (rawa, gambut, dsb).

Gambar 2. Diagram penampang perkerasan multi lapis.
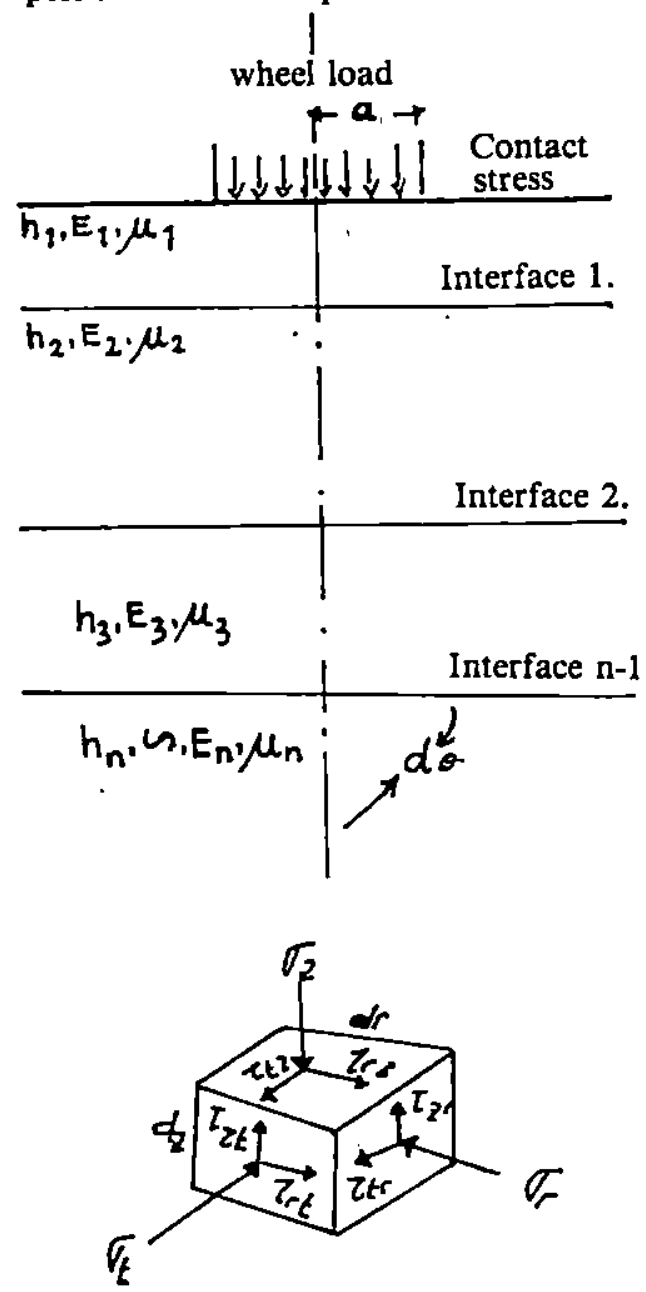
Gambar 3. Pola dasar penyebaran gaya menurut Burmister

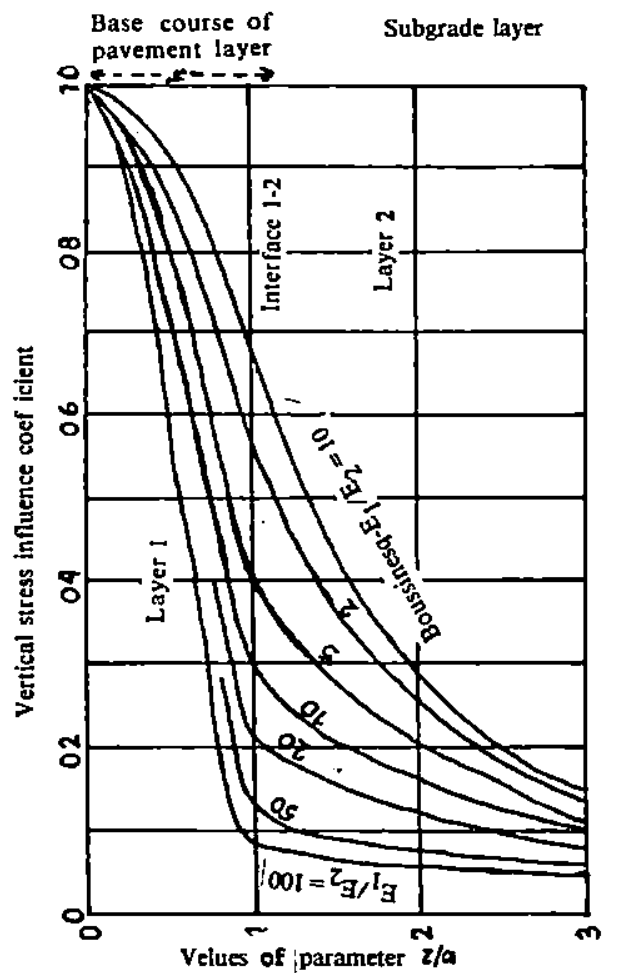

Figure 2.6. Basic patten of Burmister two-layer stress influence curves. (From Bumister, Highway Research Board Bulletin 177.)

Oleh karena itu pendekatan teoritis, meskipun sangat berguna dalam membentuk pola pikir analisa perjalanan gaya, namun tidak dapat secara memuaskan menerangkan tentang phenomena-phenomena jalan raya. Dengan kata lain, pendekatan teoritis harus dikaji secara teliti kesesuaianya dengan kondisi/iklim dimana rumus tersebut akan dipakai.

Hal-hal pokok yang berbeda (Indonesia dengan asal penelitian atau rumusan tersebut dikembangkan ditemukan) yaitu antara lain :

1. Daerah tropis kaya dengan sinar matahari termasuk adanya sinar ultra violet dan infra merah yang dapat berpengaruh terhadap proses penuaan ("ageing") bahan perkerasan terutama bitumen.

2. Daerah tropis berudara lembab dan hujan yang lebat yang mampu merongrong ketahanan tanah dasar serta mengganggu kekentalan perkerasan.

3. Negara berkembang pada umumnya terbatas dalam dana pembangunan, sehingga perlu penghematan investasi antara lain denganmenurunkan kenyaman kendaraan dan lebih mengutamakan keawetan jalan.

4. Lalu lintas di negara berkembang belum menunjukkan pola yang mantap, sehingga perbaikan prasarana lebih bersifat jangka pendek/ menengah sambil menunggu perkembangan selanjutnya.

Pertimbangan tersebut di atas menyebabkan: perlunya memodifikasi rumusan dari negara lain dan sejauh mungkin disesuaikan dengan kondisi tersebut.

\section{IV.PERTIMBANGAN DASAR}

\subsection{Pertimbangan lalu lintas.}

Pembangunan jalan pada aspekaspek tertentu sudah mengutamakan kualitas yang didasarkan kepada pemikiran-pemikiran yang konsepsional dan profesional praktis. yang tidak mengesampingkan segi-segi efisien. Pada tahapan pembangunan didapat petunjuk penggunaan konstruksi perkerasan jalan bagi berbagai kepadatan lalu lintas kurang lebih sebagai berikut : 4.1.1. Jalan dengan lalu lintas relatip tinggi, yang dibangun secara tidak bertahap, jadi langsung ketahapan proyeksi 
umpama 25 tahun, seperti halnya pada jalan-jalan bebas hambatan dan lainlain, disarankan agar kọnstruksi yang digunakan per-. kerasan beton semen.:

4.1.2. Jalan dengan lalu lintas sedang, baik yang diselenggarakan secara bertahap atau. tanpa tahapan pada umumnya dibangun konstruksi perkerasan beton aspal atáu kombinasi beton aspal.

4.1.3. Jalan dengan lalu lintas relatip rendah, pada umumnya dengan volume lalu lintas di bawah 5.000 kend.' per hari dapat dibangun konstruksi perkerasan beton aspal, beton aspal struktur rendah (HRA), Burda, Lapen, Lasbutag, Nacas dan sebagainya.

Penggunaan beton semeń untuk lalu lintas tinggi, sebenarnya sudah merupakan keharusan teknis karena :

- Konstruksi jalan raya pada hakekatnya adalah konstruksi yang banyak sekali diliputi oleh faktor-faktor ketidak pastian ("uncertainties"). Ketidak pastian terdapat pada segi lalu lintas, segi material yang digunakan dan tanah dasar yang mendukungnya.Adalah suatu kenyataan bahwa bagaimanapun telitinya pekerjaan penelitian, analisa perhitungan, dan penyelidikan yang. mendetail dilakukan, umur konstruksi jalan dan usaha-usaha pemeliharaan jalan tidak pernah sesuai dengan rencana semula.

\subsection{Pertimbangan Tehnis.}

Beberapa pertimbangan teknis yang mendukung antara lain adalah :
4.2 .1 Ữntuk konstruksi/perkerasan beton semen, kekuatan tanah pendukungnya harus dibuat relatip sama, jangan ada per- bedaan kekuatan tanah yang

$\cdots$ besar dalam jarak yang dekat.

4.2.2. Dibidang pelaksanaan,

$\because$ faktor-faktor ketidak pastian dalam pengendalian temperatur, pengendalian pemadatan, pengendalian tebal perkerasan dapat dihilangkan.

4.2. 3: Tebal perkerasan dân kualitas yang merata mudah didapatkan pada pembuatan perkerasan beton semen.

Memperhatikan itu sëmua, barangkali ada baiknya kalau salah satu aspek perkerasan jalan sebagai sumber ketidak pastian ("uncertainies") perlu dihilangkan, diganti dengan yang lebih pasti ialah penggantian "flexible pavement" dengan "rigid pavement" atau penggunaan beton semen untuk konstruksi perkerasan jalan.

v. PERENACAAN TEBAL PERKGRASAN

Methode perhitungan tebal perkerasan beton semen yang kita kenal antara laian :

\subsection{Portland Cement Association Method (PCA Method).}

Tebal perkerasan beton, semen menurut PCA Method tergantung pada :

- Magnitude and number of repeated load,

- Modulus of rupture, and

-Modulus of subgrade reaction.

Secara garis besar dapat dilihat dibawah ini. 
Tabel 1. Stress Ratio Allowable load Repetitation

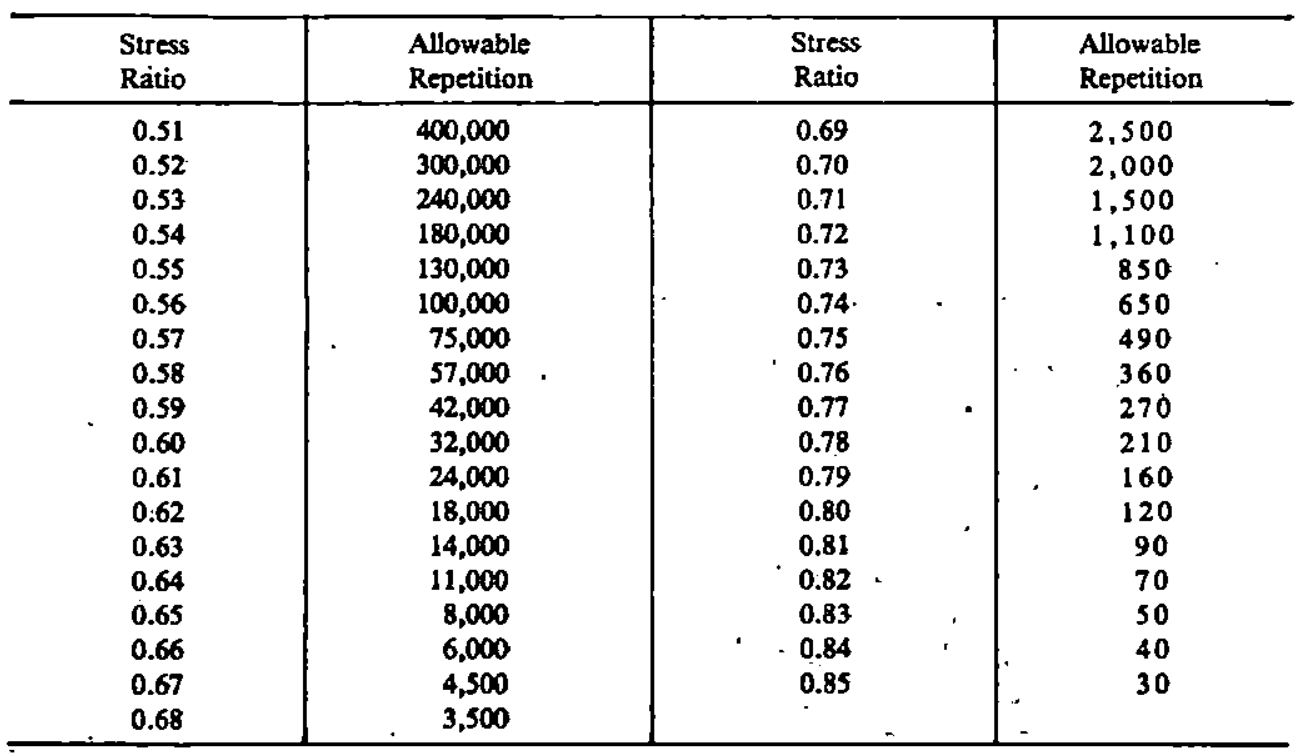
a. From Portland Cernent association
b. Load stress divided by modulus of rupture
c. Unlimitied repetition for stress rations of 0,50
or less. 


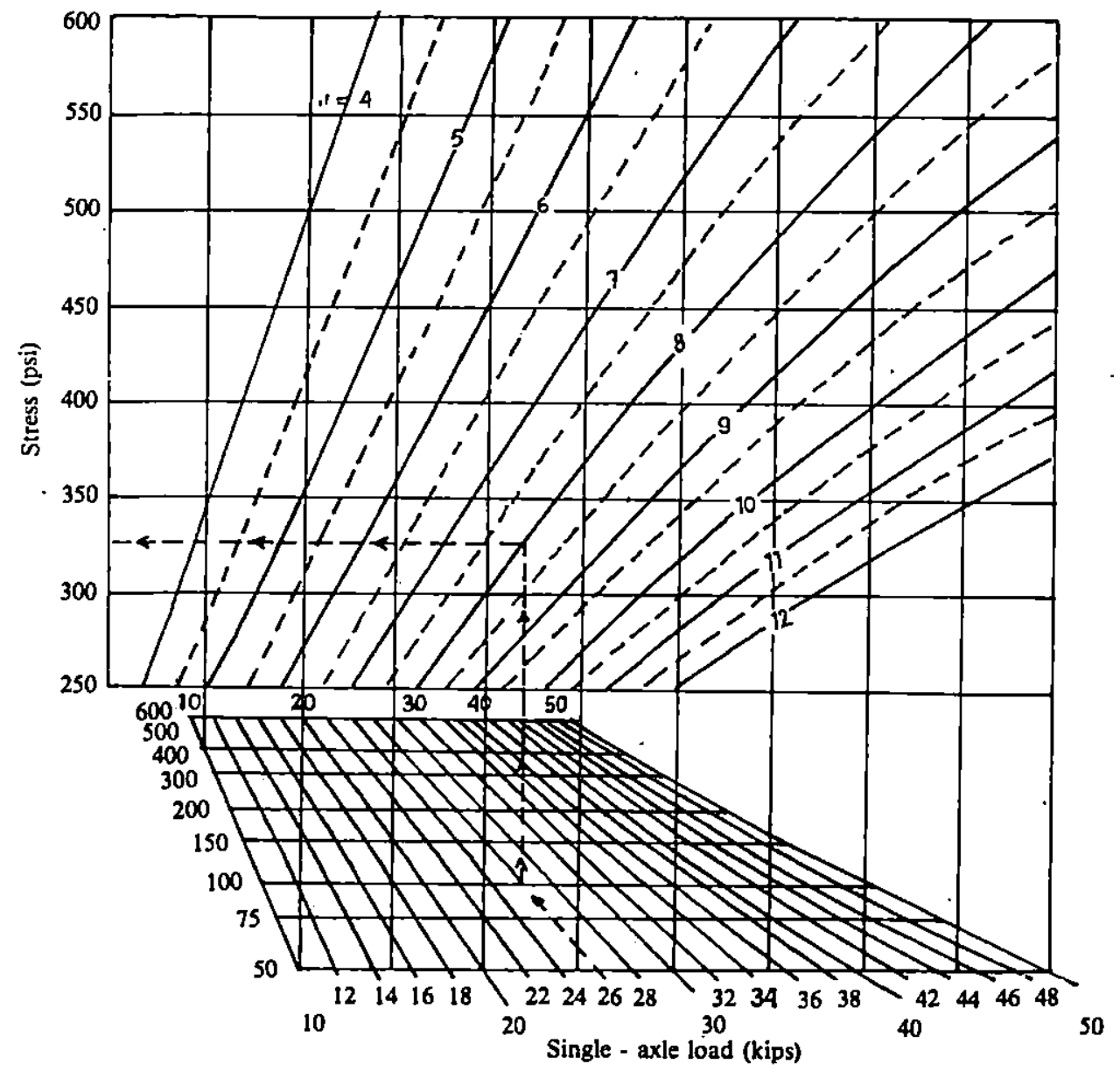




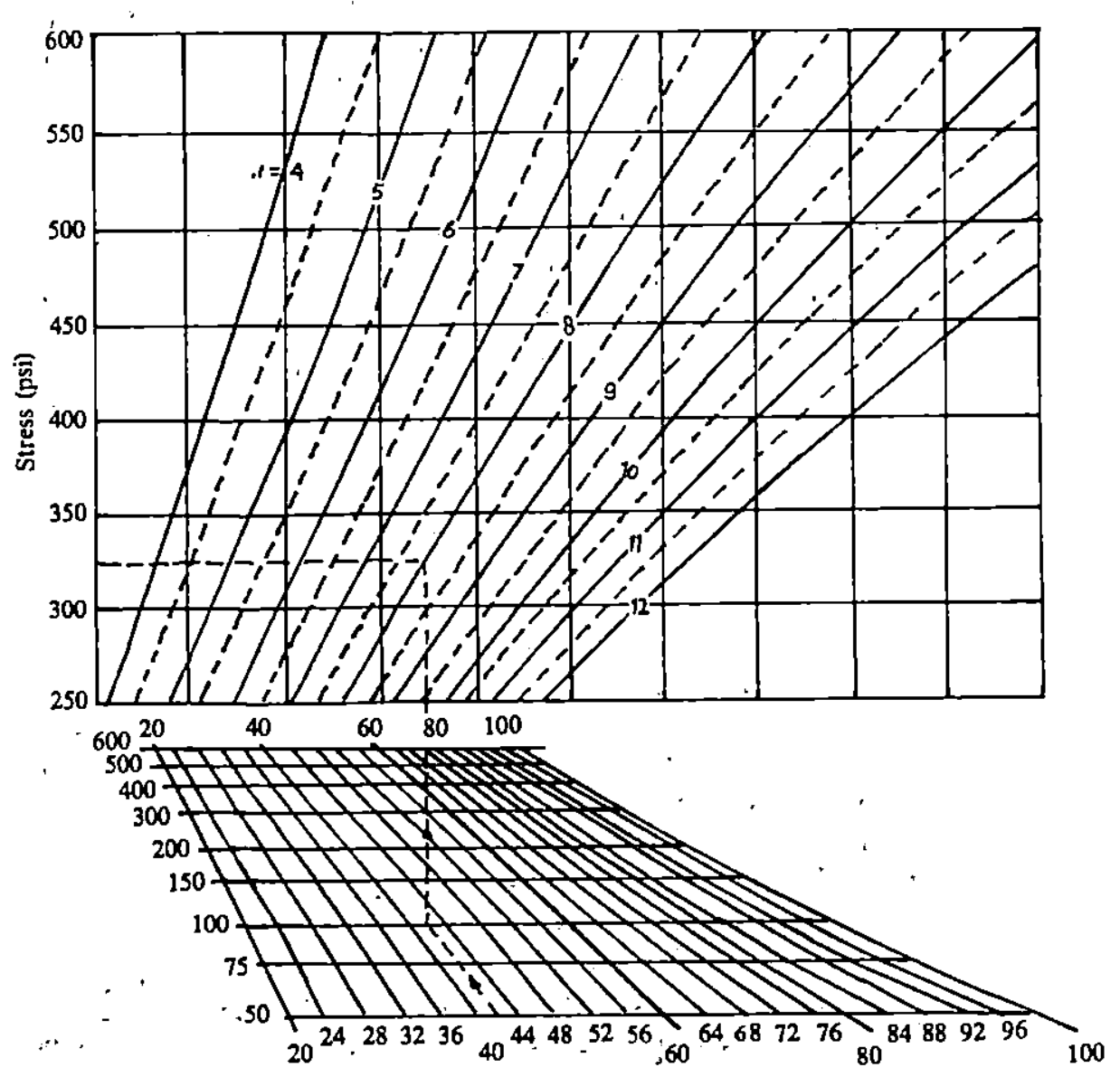

Tandem-exle load (kips) 
Total equivalent 18-kip single-axle load applications (thousands)

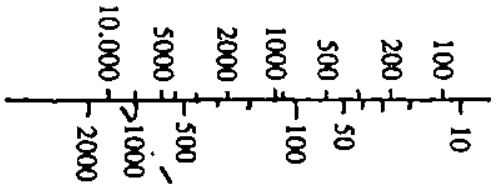

Daily equivalent $18 \cdot k i p$ single-axle load applications (20 year analysis period)

喁.

N

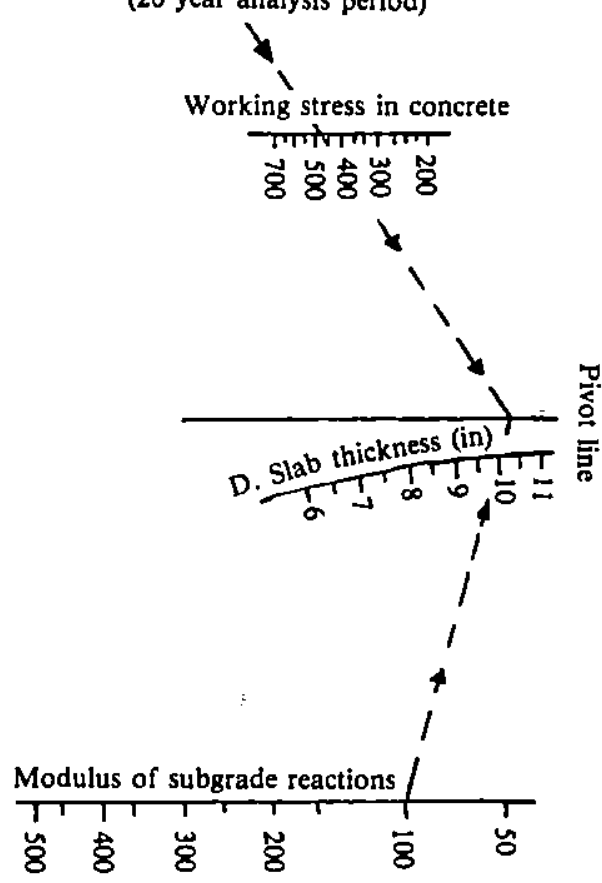

Total equivalent 18-kip single-axle load applications (thousands)

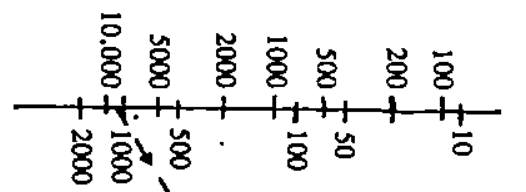

Daily equivalent 18-kip single-axle load applications

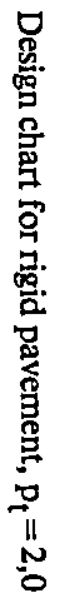

(20 year analysis period)

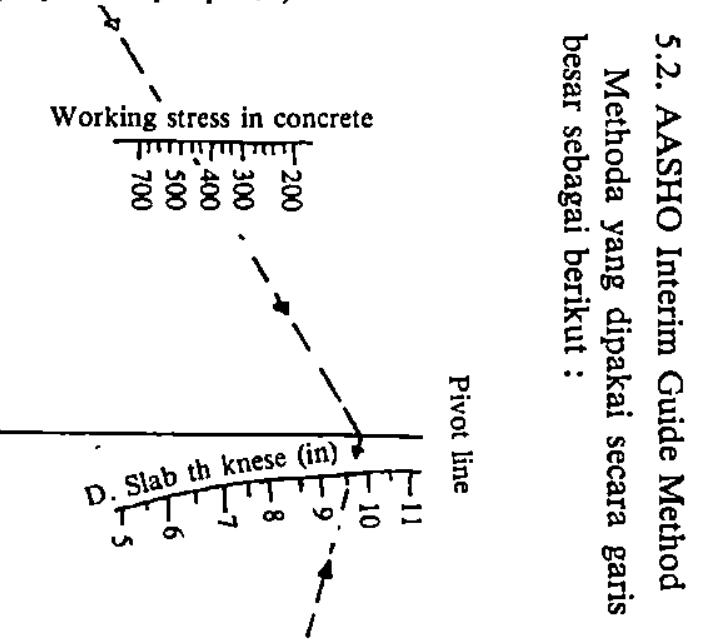

